\title{
Incidencia de Microdochium oryzae en semilla de arroz en las principales zonas de producción del Paraguay
}

\section{Incidence of Microdochium oryzae in rice seeds in the main production areas in Paraguay}

\author{
Lidia Quintana $^{1 *}$ (D), Susana Gutiérrez ${ }^{2}$ (D) Diego Arriola $^{2}$ \\ ${ }^{1}$ Universidad Nacional de Itapúa, Facultad de Ciencias Agropecuarias. \\ Encarnación, Paraguay. \\ 2 Universidad Nacional del Nordeste, Facultad de Ciencias Agrarias. \\ Corrientes, Argentina.
}

Autor correspondiente: lviedmaq@gmail.com

\begin{abstract}
Resumen: El cultivo de arroz en el Paraguay es afectado por varias enfermedades fúngicas y entre éstas, la escaldadura de la hoja de arroz causada por Microdochium oryzae. En los últimos años se observó un incremento de la enfermedad en el cultivo y la presencia del hongo en la semilla, por lo que el objetivo de esta investigación fue cuantificar la incidencia del patógeno en semillas de arroz, procedentes de las principales regiones productoras del país. Para el análisis sanitario, se colectaron semillas de arroz de la variedad IRGA 424 en distritos de los departamentos Itapúa, Misiones y Caazapá, utilizando el método del papel de filtro. El patógeno se detectó en muestras de todas las localidades analizadas, con incidencias promedio entre 0,15 y 15\%. El 53\% de las muestras analizadas, presentó una media de $2,32 \%$ de incidencia del patógeno, en tanto solo un $3 \%$ tendría una media de 20,26\% de incidencia. Estos resultados indican la necesidad de analizar semillas de otras variedades de arroz, considerando la importancia que representa la misma como fuente de inóculo para la enfermedad.
\end{abstract}

Palabras clave: Oryza sativa, Microdochium oryzae, incidencia, sanidad de semilla.

Abstract: Rice crop in Paraguay is affected by several fungal diseases and among these, the leaf rice scald caused by Microdochium oryzae. In recent years, an increase of the disease has been observed as well as the presence 
of the fungus in the seed, the objective of this research was to quantify its incidence in seed samples from the main producing area of the country. Rice seed samples of the IRGA 424 variety were collected in the districts of Itapúa, Misiones and Caazapá provinces, and the filter paper paper method was used to assess the seed health. The pathogen was detected in seeds from all the samples analyzed, with average incidences between 0.15 and $15 \% .53 \%$ of the samples analyzed had an average incidence of $2.32 \%$ of the pathogen, while only $3 \%$ would have an average incidence of $20.26 \%$. These results indicate the need to analyze seeds of other varieties of rice, considering the importance of the seed as a source of inoculum for the disease.

Keywords: Oryza sativa, Microdochium oryzae, incidence, seed health.

\section{INTRODUCCIÓN}

El cultivo de arroz (Oryza sativa L.) en Paraguay se encuentra concentrado en los departamentos de Misiones, Itapúa y Caazapá, siendo el departamento de Itapúa el mayor productor con $37 \%$ del área total de siembra. La producción nacional de arroz sin procesar ascendió a 1.083.000 ton en la campaña 2019/2020(1).

La mayoría de las enfermedades causadas por hongos son transmitidas por las semillas de arroz, la cual constituye una de las principales fuentes de inóculo para las manchas foliares. La escaldadura de la hoja de arroz es causada por Microdochium oryzae (Hashioka \& Yokogi) Samuels \& I.C. Hallet (anamorfo), Monographella albescens (Thümen) Parkinson, Sivanesan \& C. Booth (teleomorfo) ${ }^{(2-4)}$. La enfermedad fue identificada en el año 2015, en los Departamentos de Itapúa y Misiones, en las variedades IRGA 424 e IRGA 417 , con valores de $15 \%$ de incidencia promedio en las diferentes áreas analizadas ${ }^{(5)}$.

La escaldadura de la hoja se caracteriza por presentar más de un tipo de síntoma; el más frecuente es observado en ápices de hojas más viejas o basales o en los bordes de las láminas foliares como áreas necróticas en forma de franjas concéntricas de color castaño claro a oscuro en forma alternada, que a medida que se unen pueden cubrir gran parte de la hoja. Este síntoma en láminas foliares es el más común y de fácil reconocimiento en condiciones de campo(6). Las glumas de los granos de la panoja también presentan coloraciones castañas a castaño rojizo, situación por la cual $M$. oryzae, integra el complejo causal del manchado del grano de arroz ${ }^{(3,4)}$. En condiciones muy favorables para la enfermedad se pueden producir pérdidas de rendimiento cuando la planta se encuentra en estado de 
embuchamiento; los campos de arroz afectados presentan un amarillamiento generalizado con las puntas de las hojas secas(7).

A nivel mundial, esta enfermedad está presente en varios países de América, África y Asia, ocasionando pérdidas considerables manifestándose en diferentes estadios del cultivo; las semillas infectadas y los restos de cultivos, constituyen las principales fuentes de inóculo de la enfermedad $(3,4,8,9)$. La siembra de semillas infectadas provoca decoloración de plántulas, volviéndose de color oscuro(7); en evaluaciones in vitro de semillas de arroz procedente de Itajaí (Brasil), observaron que el hongo afecta la germinación, el vigor y la longitud de las raíces ${ }^{(10)}$.

En relevamientos realizados en las campañas 2014/2015, 2015/2016 y $2016 / 2017$ se ha constatado que esta enfermedad se ha ido incrementando en el cultivo ${ }^{(5,11,12)}$. Ante esta situación, se realizó el presente trabajo a fin de determinar y cuantificar la presencia del patógeno en semillas de arroz procedente de diferentes regiones productivas del Paraguay.

\section{METODOLOGÍA}

La investigación se realizó en el laboratorio de Microbiología de la Facultad de Ciencias y Tecnología de la Universidad Nacional de Itapúa (UNI), durante la campaña 2017/2018. Se analizaron muestras de semillas de arroz de la variedad IRGA 424 procedentes de los distritos de Gral. Delgado, Fram y Coronel Bogado (departamento de Itapúa), Santa Bárbara, Yuty (departamento de Caazapá), Santa María, Yabebyry, San Juan Bautista (departamento de Misiones). El método utilizado fue el del papel de filtro o blotter test(13).

Fueron sembradas 400 semillas por muestra, en bandejas de plástico conteniendo tres capas de papel de filtro humedecidas con agua estéril. Se realizaron 4 repeticiones de 100 semillas cada una, en condiciones de laboratorio, a una temperatura de $24 \pm 2^{\circ} \mathrm{C}$, durante 10-12 días de incubación(13).

El patógeno fue identificado mediante sus estructuras reproductivas (esporodoquios y conidios) observados bajo el microscopio estereoscópico (90 x) y al microscopio óptico (400x) montando el material en agua estéril, consultando la bibliografía específica ${ }^{(8,9)}$. El porcentaje de incidencia (I) del patógeno se obtuvo por medio de la fórmula I=SI (semillas infectadas por $M$. oryzae)/SS (total de semillas sembradas) x100(8). Con los valores de incidencia obtenidos se realizó un histograma de frecuencias (Figura 1). 


\section{RESULTADOS Y DISCUSIÓN}

En las muestras de semillas de arroz de la variedad IRGA 424, se detectó la presencia del hongo Microdochium oryzae, ocasionando síntomas tales como muerte de raicillas y coleóptilos, mientras algunas semillas no germinaron. Asociado a las semillas enfermas, el hongo desarrolló micelio aéreo algodonoso, de color blanco con esporodoquios de color salmón; al microscopio óptico fue confirmada la presencia de M. oryzae, al observar los conidios falcados, unicelulares, hialinos cuando jóvenes y de dos células cuando maduros, a veces hasta tres septos (no estrechados en el septo). Se resalta la importancia de la diferenciación de los esporodoquios acompañados de masa de esporas de color salmón para la detección de la enfermedad.

En la Tabla 1 se presentan los valores promedios de incidencias de las 4 repeticiones obtenidas por distrito y las incidencias promedio por distrito, la cual varió entre 0,15 y $15 \%$. El patógeno fue identificado en todas las muestras procedentes de los diferentes distritos.

Tabla 1. Incidencia (\%) de Microdochium oryzae en semillas de arroz.

\begin{tabular}{|c|c|c|c|c|c|c|}
\hline \multirow{2}{*}{$\begin{array}{c}\text { Departa } \\
\text { mento }\end{array}$} & Distrito & \multirow{2}{*}{$\begin{array}{c}\text { Incidencia } \\
(\%) \\
\text { promedio } \\
\text { por } \\
\text { distrito } \\
15\end{array}$} & \multicolumn{4}{|c|}{$\begin{array}{l}\text { Incidencia }(\%) \text { promedio por } \\
\text { repeticiones }\end{array}$} \\
\hline & Gral Delgado & & 15 & 15 & 22,5 & 7,5 \\
\hline & Fram & 6,0 & 2,5 & 10 & 4,5 & 7,0 \\
\hline & $\begin{array}{l}\text { Coronel } \\
\text { Bogado }\end{array}$ & 5,5 & 3,5 & 4,5 & 5,5 & 8,5 \\
\hline \multirow[t]{2}{*}{ Caazapá } & $\begin{array}{l}\text { Santa } \\
\text { Barbara }\end{array}$ & 1,5 & 0,5 & 0,25 & 2,25 & 3,0 \\
\hline & Yuty & 0,15 & 0,1 & 0,25 & 0,15 & 0,1 \\
\hline \multirow[t]{3}{*}{ Misiones } & $\begin{array}{l}\text { San Juan } \\
\text { Bautista }\end{array}$ & 12,5 & 9,5 & 11 & 14,5 & 15 \\
\hline & Santa María & 8,0 & 6,5 & 10 & 4,5 & 8,0 \\
\hline & Yavevyry & 2,5 & 0,5 & 3,25 & 2,5 & 3,5 \\
\hline
\end{tabular}

En la Tabla 2 se diferencian los valores de medias de cada clase y su correspondiente valor de frecuencia relativa y absoluta. Asimismo, en el gráfico de barras (Figura 1), se indica la frecuencia relativa (eje de ordenadas) y el porcentaje de incidencia (eje de abscisas). Este análisis, explicaría que el $53 \%$ de las muestras analizadas, se aproxima a una media de $2,32 \%$ de incidencia del patógeno, mientras el $19 \%$ de las mismas, 
corresponde a una media de $6,80 \%$, en tanto el $13 \%$ de las muestras de semillas estudiadas, se ubica entre 11,30 y $15,78 \%$ de incidencia. Solo un $3 \%$ tendría una media de $20,26 \%$ de incidencia.

Tabla 2. Frecuencias relativas y absolutas obtenidas con los datos de incidencia de M. oryzae

\begin{tabular}{l|lllll}
\hline CLASE & LI & LS & MC & FA & FR \\
\hline $\mathbf{1}$ & 0.10 & 4.58 & 2.34 & 17 & 0.53 \\
$\mathbf{2}$ & 4.58 & 9.06 & 6.82 & 6 & 0.19 \\
$\mathbf{3}$ & 9.06 & 13.54 & 11.30 & 4 & 0.13 \\
$\mathbf{4}$ & 13.54 & 18.02 & 15.78 & 4 & 0.13 \\
$\mathbf{5}$ & 18.02 & 22.50 & 20.26 & 1 & 0.03 \\
\hline
\end{tabular}

Li: límite inferior, Ls: límite superior, MC: media de clase, Fa: frecuencia absoluta Fr: frecuencia relativa.

Las características sintomáticas y morfológicas del patógeno en las semillas analizadas, fueron coincidentes con lo reportado por varios autores de la literatura mundial $(3,4,8,9)$.

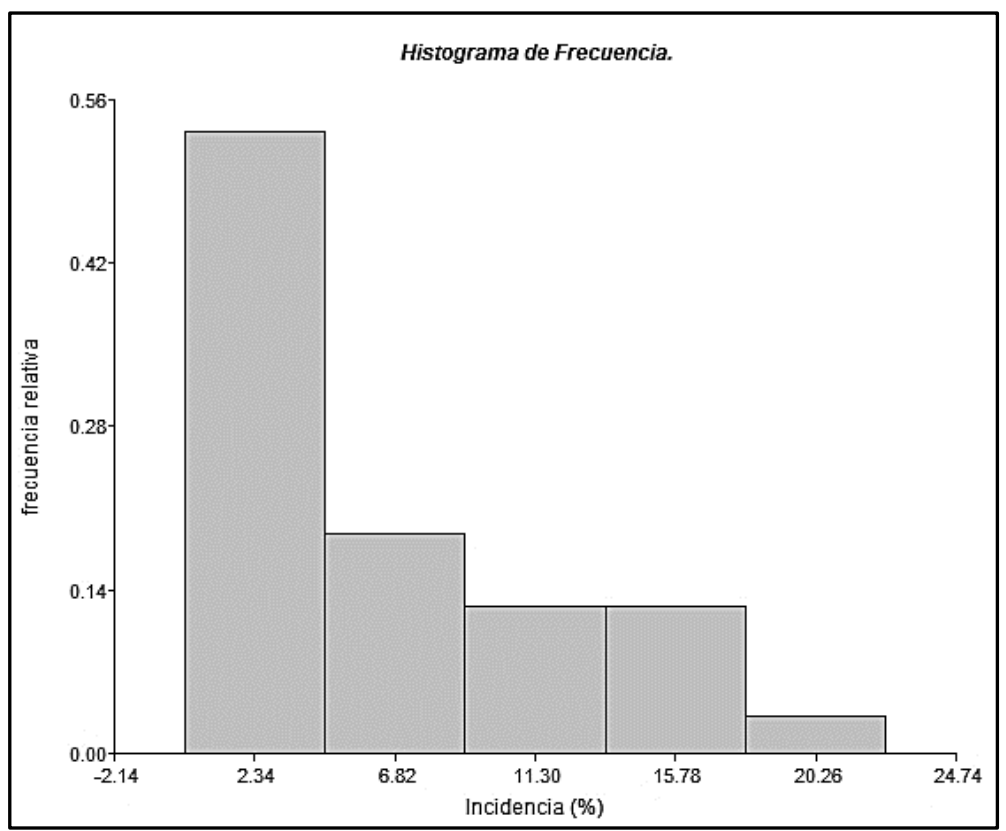

Figura 1. Frecuencia relativa y valores medios de incidencia correspondiente a cada clase determinada. 
Con respecto a las incidencias del hongo en semilla, los valores correspondieron a 0,15 a $15 \%$ en las semillas analizadas. Dichos valores se aproximarían a lo observado en semilla de otros países de la región, cuyos autores utilizaron el método del papel de filtro o blotter test. En el año 2001, en Brasil determinaron un valor de $18 \%$ en semillas de arroz de la región de Rio Grande do Sul (RS)(14). Posteriormente, en 2007 autores brasileños también reportaron niveles de 4,9\% y $24,6 \%$ de incidencia respectivamente en RS y Sao Paulo (15,16). En tanto, en Argentina en el año 2009 se obtuvieron $4 \%$ de incidencia promedio en lotes de semilla provenientes de zonas de producción del nordeste(17).

\section{CONCLUSIÓN}

La presencia del hongo Microdochium oryzae en semillas de arroz proveniente de los departamentos de Itapúa, Misiones y Caazapá constituye una fuente de inóculo de importancia para la presencia de la escaldadura de la hoja en la región arrocera del país. Se considera necesario analizar su presencia en otras variedades de arroz.

\section{FUENTE DE FINANCIACIÓN}

La investigación fue financiada por PROCIENCIA-CONACYT.

\section{PARTICIPACIÓN DE AUTORES}

LQ: procesamiento de muestras y redacción del texto; DA: análisis de datos; SG: corrección del texto.

\section{CONFLICTO DE INTERÉS}

Los autores declaran no tener conflicto de interés.

\section{REFERENCIAS BIBLIOGRÁFICAS}

1. Ministerio de Agricultura y Ganadería, MAG. Síntesis estadísticas de Producción agropecuaria [Internet]. 2021 [Acceso 20 ene 2021]. Disponible5en: http://www.mag.gov.py/index.php/institucion/dependencias/sintesisestadistica

2. Hernandez-Restrepo M, Groenewald JZ, Crous PW. Taxonomic and phylogenetic re-evaluation of Microdochium, Monographella and Idriella. Persoonia [Internet]. 2016 [Acceso 20 feb 2021]. Disponible en: https://dx.doi.org/10.3767\%2F003158516X688676

3. Ou SA. Rice diseases. 2nd. ed. Kew: Surrey, England; 1985. 380 p. 
4. Webster RK, Gunnell PS. Compendium of Rice Diseases. St. Paul, Minnesota, USA: The American Phytopathological Society; 1992, 92 p.

5. Quintana de Viedma L, Gutiérrez S, Maidana M, Arriola M, Morínigo K. Incidencia de patógenos causantes de manchas foliares del cultivo del arroz en la Campaña 2014/2015 en Paraguay. Revista sobre Estudios e Investigaciones del Saber Académico [Internet]. 2016 [Acceso 20 abril 2021];10(10):103-106. Disponible en: http://publicaciones.uni.edu.py/index.php/eisa/article/view/122/97

6. Mazzanti de Castañón MA, Gutiérrez SA. Enfermedades del cultivo del arroz en Argentina. Fitopatología Brasileira, 2001(Supl.):471.

7. Filippi MC, Prabhu, AS, da Silva, GB. Escaldadura do arroz e seu controle. Circular Técnica 72 Embrapa Arroz e Feijão [Internet]. Goiás; 2005 [Acceso 10 de diciembre 2020]. Disponible: https://www.agencia.cnptia.embrapa.br/Repositorio/circ_72_000fyudg qsb02wx5ok076ralotbs06q1.pdf

8. Mew TW, Misra, JK. A Manual of Rice Seed Health Testing. Manila, Philippines, International Rice Research Institute. [Internet]; 1994 [Acceso 12 diciembre 2020]. 113 p; disponible en https://www.semanticscholar.org/paper/A-manual-of-rice-seed-healthtesting.-Mew-Misra/e94672985bb24034e03a281849d08e4f9283809b

9. Mew TW, Gonzales P. A handbook of rice seedborne fungi. Los Baños, Laguna, International Rice Research Institute. [Internet]. 2002 [Acceso 12 diciembre 2020]. 83 p. Disponible en: http://books.irri.org/9712201740_content.pdf

10. Scheidt BT, García, J, Trezzi Casa R, Medeiros Cohelo CM. Microdochium albescens may affect the physiological quality of irrigated rice cultivar seeds. Ciência Rural [Internet]. 2021; [Acceso 20 abril 2021];51(7):1-5. Disponible en: https://www.scielo.br/scielo.php?pid=S0103$84782021000700152 \&$ script=sci_arttext\&tlng=en

11. Quintana L, Gutiérrez S, Ortiz A. Prevalence of fungi associated with rice leaf spot in the main rice-growing areas in Paraguay. Australian Journal of Basic and Applied Sciences [Internet]. 2019 [Acceso 15 febrero 2021];(8):60-63. Disponible en: http://ajbasweb.com/old/ajbas/2019/August/60-63(9).pdf

12. Quintana L, Gutiérrez S, Ortíz, A. Microdochium oryzae associated with rice leaf scald disease in Paraguay. Australian Journal of Basic and Applied Sciences [Internet]. 2018 [Acceso 20 abril 2021]:12(7):56-58. Disponible en: http://www.ajbasweb.com/old/ajbas/2018/July/5658(8).pdf

13. Mathur SB, Kongsdal O. Common laboratory seed health testing methods for detecting fungi. 3rd ed. Copenhagen, Denmark; 2003, 425 p. 
14. Gutiérrez SA, Carmona MA, Reis EM. Estudio preliminar sobre métodos de detección de Microdochium oryzae en semillas de arroz. Tropical Plant Pathology. 2009;4:42-44.

15. Franco DF, Ribeiro AS, Nunes C, Ferreira E. Fungos associados a sementes de arroz irrigado no Rio Grande do Sul. Revista Brasileira de Agrociência. 2001;7:235-236. Disponible en: http://www.ufpel.tche.br/faem/agrociencia/v7n3/artigo16.pdf

16. Farias CRJ de, Afonso Schneid AP, Brancão Fernandes, M, Pierobom CR. Incidência de fungos associados a sementes de arroz em seis regiões produtoras do Rio Grande do Sul. Revista Brasileira de Agrociência. 2007;14:487-490. Disponible en: https://periodicos.ufpel.edu.br/ojs2/index.php/CAST/article/viewFile/ $1395 / 1381$

17. Malavolta VMA, Arruda Soligo E, Dias Luiz EA, Bastos CR. Incidência de fungos e quantificação de danos em sementes de genótipos de arroz. Summa Phytopathologica. 2007;33:280-286. Disponible en: https://www.scielo.br/j/sp/a/5GYCcjyzQcp8V59dqjGbqsN/?lang=pt 